\title{
Produtividade e qualidade de grãos de arroz irrigado em safras com regimes térmicos distintos na floração
}

\author{
Natalia Maria de Souza', Rubens Marschalek² e Luis Sangoi ${ }^{1}$
}

\begin{abstract}
Resumo - A temperatura é um dos fatores climáticos mais importantes para o cultivo de arroz. Temperaturas acima de $35^{\circ} \mathrm{C}$ limitam a produção deste cereal, podendo acarretar prejuízos irreversíveis à produtividade. A antese é a fase mais sensível do arroz à ocorrência de altas temperaturas. Este trabalho foi conduzido com o objetivo de avaliar o desempenho agronômico e a qualidade de grãos de cinco genótipos (Epagri 109, SCS116 Satoru, SCS121 CL, SCS122 Miura e SC 676), em duas safras agrícolas (2016/17 e 2017/18), correlacionando-os com a temperatura do ar durante a antese e o enchimento de grãos. Avaliaram-se a esterilidade de espiguetas, a produtividade, a massa de 1.000 grãos e aspectos qualitativos de pós-colheita (rendimento de engenho e percentual de gesso). As temperaturas observadas na safra 2016/17 da antese até a colheita foram superiores às observadas na safra $2017 / 18$, apresentando médias de 30,5 e $28,5^{\circ} \mathrm{C}$ e temperaturas máximas de 34,3 e $30,9^{\circ} \mathrm{C}$ para cada safra, respectivamente. As temperaturas mais elevadas na primeira safra reduziram a produtividade, a massa de 1.000 grãos e o rendimento de engenho. Elas também aumentaram a esterilidade de espiguetas e o percentual de gesso. A linhagem SC676 apresentou a maior produtividade $\left(13.070 \mathrm{~kg} \mathrm{ha}^{-1}\right)$, porém foi o genótipo com pior qualidade de grãos.
\end{abstract}

Termos para indexação: Oryza sativa; Calor; Esterilidade; Qualidade de grãos.

\section{Grain yield and quality of irrigated rice in seasons with different thermal regimes at flowering}

Abstract - Temperature is one of the most important climatic factors for rice production. Temperatures above $35^{\circ} \mathrm{C}$ limit the production of this cereal, damaging irreversibly its yield. Anthesis is the most sensitive phase of rice to the occurrence of high temperatures. This experiment was carried out aiming to evaluate the agronomic performance and grain quality of five rice genotypes (Epagri 109, SCS116 Satoru, SCS121 CL, SCS122 Miura and SC 676) at two growing seasons (2016/17 and 2017/18), correlating them with the air temperature during anthesis and grain filling. The following variables were assessed: spikelet sterility, yield, mass of 1,000 grains and postharvest qualitative aspects (milling yield and chalky grain percentage). The temperatures recorded in the 2016/17 growing season from anthesis to harvest were higher than in $2017 / 18$. They present averages of 30.5 and $28.5^{\circ} \mathrm{C}$ and maximum temperatures of 34.3 and $30.9^{\circ} \mathrm{C}$ for each experimental year, respectively. The higher temperatures of the first growing season reduced grain yield, 1,000 grain mass and milling yield. They also increased spikelet sterility and chalky grains. The inbreed line SC 676 presented the highest yield $\left(13,070 \mathrm{~kg} \mathrm{ha}^{-1}\right)$, however, it was also the genotype with worst grain quality.

Index terms: Oryza sativa; Heat; Sterility; Grain quality.

\section{Introdução}

O arroz é um cereal amplamente cultivado, podendo ser produzido em diferentes condições ambientais, sistemas de produção e regiões geográficas. Em função disto, as plantas ficam sujeitas à ocorrência de temperaturas desfavoráveis durante seu cultivo. A temperatura é um dos elementos climáticos de maior importância para a cultura. Temperaturas elevadas podem prejudicar todo o cultivo, da germinação à maturação de grãos (SOSBAl, 2016). O período reprodutivo é o mais sensível às altas temperaturas, principalmente durante a antese, onde a ocorrência de ventos quentes afeta a fecundação dos estigmas, reduzindo o número de grãos formados (CHEN et al., 2017).

A aparência dos grãos de arroz é prejudicada quando o seu desenvolvimento ocorre sob temperatura elevada, tornando-os gessados, o que afeta o polimento e leva à quebra dos grãos durante o beneficiamento (ALI et al., 2019; CHEN et al., 2017; LYMAN et al., 2013; SREENIVASULU et al., 2015; ZHAO
\& FITZGERALD, 2013). A formação de gesso durante o enchimento dos grãos sob temperatura alta ocorre devido ao acúmulo irregular de fotoassimilados no endosperma, o que reduz a resistência do grão às forças aplicadas durante o beneficiamento, predispondo a uma quebra quando os grãos estão sendo polidos, afetando diretamente o rendimento de engenho (LONDERO et al., 2015).

Diante da instabilidade térmica e da constância de mudanças climáticas nos últimos anos, a ocorrência de altas

Recebido em 4/5/2020. Aceito para publicação em 18/6/2020.

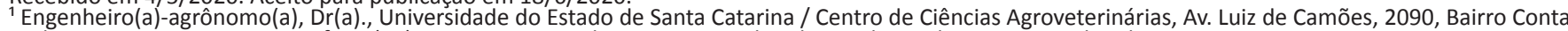

Dinheiro, 88520-000 Lages, SC, fone (49) 3289 9294, e-mail: naty_natynatalia@hotmail.com, luis.sangoi@udesc.br.

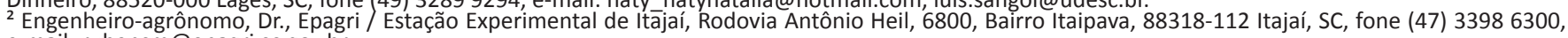
e-mail: rubensm@epagri.sc.gov.br. 
temperaturas durante o ciclo de cultura do arroz é comum no sul do Brasil, que abrange os dois maiores produtores nacionais deste cereal, Rio Grande do Sul e Santa Catarina (SOSBAI, 2016). Apesar da evolução da produtividade, observa-se uma redução nos anos em que ocorrem temperaturas altas na fase reprodutiva da cultura, o que afeta também a qualidade de grãos. Registros de redução da produtividade devido ao estresse por altas temperaturas foram identificados em diversas safras em Santa Catarina. Um exemplo disto ocorreu na safra 2009/10, na qual temperaturas entre 33 e $40^{\circ} \mathrm{C}$ foram registradas, por períodos de três a sete dias, durante os meses de janeiro a março. Este estresse diminuiu a produtividade e a qualidade de grãos nas principais regiões produtoras de arroz do Estado (EBERHARDT, 2010).

Este trabalho foi conduzido com objetivo de avaliar a produtividade e a qualidade dos grãos de genótipos de arroz irrigado em duas safras agrícolas com diferentes regimes térmicos.

\section{Material e métodos}

O experimento foi conduzido no município de Itajaí, SC, durante as safras de 2016/17 e 2017/18. O delineamento experimental foi inteiramente casualizado com três repetições e esquema bifatorial (5x2), sendo o primeiro fator os genótipos utilizados (as cultivares SCS122 Miura, SCS121 CL, Epagri 109 e SCS116 Satoru e a linhagem SC 676) e o segundo fator as safras com diferentes regimes térmicos. Os genótipos são pertencentes à subespécie índica e apresentam ciclo tardio.

Os experimentos foram conduzidos no sistema pré-germinado de cultivo. As semeaduras foram realizadas em 29/09/2016 e 26/10/2017, com densidade de $120 \mathrm{~kg} \mathrm{ha}^{-1}$ de sementes nos dois anos. As parcelas tinham $2 \times 5 \mathrm{~m}$ de dimensão total e uma área útil de $1,5 \mathrm{x}$ $4 \mathrm{~m}$.

O manejo da cultura nos experimentos seguiu as recomendações da Sosbai (2016), com aplicações de uma dose de $\mathrm{P}_{2} \mathrm{O}_{5}$ na base e três doses de $\mathrm{N}+\mathrm{K}_{2} \mathrm{O}$ na cobertura, nos estádios V2, V4 e V8 (COUNCE et al., 2000). Durante o cultivo foram realizadas pulverizações de fungicidas nas combinações de Tebuconazol + Trifloxystrobina e Triazol + Estrobirulina, o que propiciou ausência de doenças durante o cultivo das plantas de arroz deste experimento.

A antese foi determinada quando $50 \%$ das panículas de cada genótipo, em cada safra, estavam no estádio R4 (COUNCE et al., 2000), ocorrendo de $17 / 01 / 2017$ a 29/01/2017 e 05/02/2018 a 23/02/2018, na 1a e 2a safra, respectivamente. As colheitas ocorreram em $13 / 03 / 2017$ e $22 / 03 / 2018$. Elas foram efetuadas com colheitadeira de parcelas automatizada Classic/Weitersteiger numa área útil de $6 \mathrm{~m}^{2}$ para determinação da produtividade, que foi expressa em kg ha-1 ${ }^{-1}$ na umidade de $13 \%$.

Para determinação da esterilidade foram colhidas amostras de $1 \mathrm{~m}^{2}$ em cada parcela, que foram secadas e debulhadas manualmente. Em seguida, separaram-se as espiguetas cheias e estéreis, que foram contadas no contador de grãos Sanick ESC 2008. Posteriormente, determinou-se o percentual de esterilidade de espiguetas das parcelas. As espiguetas cheias foram utilizadas para determinação da massa de 1.000 grãos que também foi expressa na umidade de $13 \%$.

Para avaliação dos aspectos de póscolheita (rendimento industrial e qualidade de grãos) foram pesadas $50 \mathrm{~g}$ de cada parcela. Estas amostras foram processadas no engenho de prova - Suzuki, para obtenção de arroz descascado e polido. Em seguida, as amostras foram submetidas à análise no scanner de grãos Image - Rice Grain Scanner (Selgron), que está ligado a um computador acoplado a um sistema digital de captura de imagens e um software de análise de grãos. As variáveis utilizadas foram o rendimento de engenho, o percentual de grãos gessados e o percentual de área gessada dos grãos. A determinação do percentual de grãos gessados levou em consideração o percentual de grãos que apresentavam centro bran$\mathrm{co}$, independentemente do tamanho. A área gessada dos grãos foi determinada considerando o percentual total da área gessada na amostra.

Os dados obtidos foram avaliados estatisticamente através da análise de variância, utilizando o programa Assis- tat Software Version 7.7 (SILVA \& AZEVEDO, 2016). Os valores de $F$ foram considerados ao nível de significância de $5 \%(P<0,05)$. Quando significativas, as médias foram comparadas pelo teste de Tukey, também ao nível de $5 \%$ de probabilidade de erro.

\section{Resultados e discussão}

Houve diferenças climáticas importantes entre as safras quanto à temperatura e radiação solar (Tabela 1 ). $\mathrm{Na}$ safra 2016/17, a temperatura média do cultivo, entre semeadura e colheita, foi de $28,1^{\circ} \mathrm{C}$. Do florescimento (R4) até a maturação de colheita (R9), a temperatura média foi de $30,5^{\circ} \mathrm{C}$. Considerando apenas o florescimento, a temperatura média foi $30,6^{\circ} \mathrm{C}$, com máxima observada de $34,3^{\circ} \mathrm{C}$. Na safra seguinte (2017/18), a temperatura média durante o ciclo total também foi de $28,1^{\circ} \mathrm{C}$. Contudo, do florescimento (R4) até a maturação de colheita (R9) a temperatura média foi de $28,5^{\circ} \mathrm{C}$. Considerando apenas o florescimento, a temperatura média foi menor $\left(28,2^{\circ} \mathrm{C}\right)$, com temperatura máxima de $30,9^{\circ} \mathrm{C}$ (Tabela 1 ). A safra 2016/17 registrou a maior disponibilidade de radiação, em todas as fases do ciclo da cultura, o que contribuiu para os maiores valores de temperatura na mesma (INMET, 2019).

A análise de variância mostrou que o efeito do fator genótipo foi significativo para produtividade (Tabela 3) e do fator safra para produtividade, esterilidade e rendimento de engenho (Tabela 2). Houve interação significativa entre safra e genótipo somente para as variáveis massa de 1.000 grãos e gesso dos grãos (Tabela 3).

Houve um aumento de $3,7 \%$ na esterilidade de espiguetas da safra 2017/18 para a 2016/17 (Tabela 2), quando as temperaturas mais elevadas foram registradas durante a antese. Temperaturas acima de $32,6^{\circ} \mathrm{C}$ durante a floração podem causar até $50 \%$ de esterilidade (NGUYEN et al., 2014), enquanto valores acima de $35^{\circ} \mathrm{C}$ causam até $100 \%$ de esterilidade, dependendo do genótipo (VAN OORT et al., 2014). Altas temperaturas na antese promovem a redução ou o impedimento da deiscência de anteras, da liberação de grãos de pólen e da 
Tabela 1. Temperatura e radiação solar em diferentes fases do ciclo do arroz, nas safras de 2016/17 e 2017/18

Table 1. Temperature and solar radiation at different stages of the rice cycle, in the 2016/17 and 2017/18 growing seasons

\begin{tabular}{|c|c|c|c|c|}
\hline \multirow{2}{*}{ Fase } & \multicolumn{2}{|c|}{ Temperatura média $\left({ }^{\circ} \mathrm{C}\right)$} & \multicolumn{2}{|c|}{ Radiação solar média $\left(\mathrm{kJ} \mathrm{m}^{-2}\right)$} \\
\hline & $2016 / 17$ & $2017 / 18$ & 2016/17 & $2017 / 18$ \\
\hline Antese (R4) & 30,6 & 28,2 & $4.743,9$ & $4.527,6$ \\
\hline Antese à maturação (R4-R9) & 30,5 & 28,5 & $4.210,3$ & $3.693,6$ \\
\hline
\end{tabular}

Tabela 2. Esterilidade de espiguetas (\%), produtividade $\left(\mathrm{kg} \mathrm{ha}^{-1}\right)$ e rendimento de engenho (\%) em safras com temperaturas distintas, na média de cinco genótipos

Table 2. Spikelet sterility (\%), productivity $\left(\mathrm{kg} \mathrm{ha}^{-1}\right)$ and milling yield (\%) in growing seasons with different temperatures, averaging five genotypes

\begin{tabular}{cccc}
\hline & $2016 / 17$ & $2017 / 18$ \\
\hline Esterilidade de espiguetas (\%) & $17,3 \mathrm{~A}^{*}$ & $13,6 \mathrm{~B}$ & $\mathrm{CV} \%=21,92$ \\
Produtividade $\left(\mathrm{kg} \mathrm{ha}^{-1}\right)$ & $11.123 \mathrm{~B}^{*}$ & $12.714 \mathrm{~A}$ & $\mathrm{CV} \%=7,27$ \\
Rendimento de engenho (\%) & $64,8 \mathrm{~B}^{*}$ & $69,3 \mathrm{~A}$ & $\mathrm{CV} \%=4,74$ \\
\hline
\end{tabular}

*Médias seguidas de mesma letra maiúscula na linha não diferem pelo teste de Tukey $(p \leq 0,05)$.

Tabela 3. Produtividade ( $\left.\mathrm{kg} \mathrm{ha}^{-1}\right)$ dos genótipos avaliados, na média de duas safras, e massa de 1.000 grãos (g), grãos gessados (\%) e área gessada (\%) nas duas safras com regimes térmicos distintos

Table 3. Yield $\left(\mathrm{kg} \mathrm{ha}^{-1}\right)$ of the evaluated genotypes, averaging two harvests, and a mass of 1,000 grains (g), chalky grains (\%) and chalky area (\%) in the two growing seasons with different thermal regimes

\begin{tabular}{|c|c|c|c|c|c|c|c|}
\hline & \multirow{2}{*}{$\begin{array}{l}\text { Produtividade } \\
\qquad\left(\mathrm{kg} \mathrm{ha}^{-1}\right)\end{array}$} & \multicolumn{2}{|c|}{ Massa de 1.000 grãos (g) } & \multirow{2}{*}{$\begin{array}{l}\text { Grãos } \\
2016 / 17 \\
\end{array}$} & \multirow{2}{*}{$\begin{array}{r}\text { gessados (\%) } \\
2017 / 18 \\
\end{array}$} & \multirow{2}{*}{$\begin{array}{l}\text { Área } \\
2016 / 17 \\
\end{array}$} & \multirow{2}{*}{$\begin{array}{r}\text { gessada (\%) } \\
2017 / 18\end{array}$} \\
\hline & & $2016 / 17$ & $2017 / 18$ & & & & \\
\hline SC 676 & $13.070 a^{*}$ & $27,9 \mathrm{Bab}^{*}$ & $30,1 \mathrm{Aa}$ & $17,4 \mathrm{Aa} *$ & $5,1 \mathrm{Ba}$ & $13,8 \mathrm{Aa} *$ & $2,7 \mathrm{Ba}$ \\
\hline SCS122 Miura & $12.298 \mathrm{ab}$ & $26,9 \mathrm{Bb}$ & $30,0 \mathrm{Aa}$ & 7,3 Ab & 3,2 Bab & $4,6 \mathrm{Ab}$ & 1,8 Bab \\
\hline SCS116 Satoru & $11.962 \mathrm{abc}$ & $28,3 \mathrm{Ba}$ & $30,1 \mathrm{Aa}$ & $6,4 \mathrm{Abc}$ & 2,8 Bab & $3,3 \mathrm{Abc}$ & 1,5 Bab \\
\hline Epagri 109 & $11.501 \mathrm{bc}$ & $28,9 \mathrm{Aa}$ & $29,6 \mathrm{Aa}$ & $6,0 \mathrm{Abc}$ & 3,1 Bab & $3,9 \mathrm{Abc}$ & 1,9 Bab \\
\hline \multirow[t]{2}{*}{ SCS121 CL } & $10.760 \mathrm{c}$ & $28,0 \mathrm{Bab}$ & $30,4 \mathrm{Aa}$ & 4,4 Ac & $1,5 \mathrm{Bb}$ & $2,1 \mathrm{Ac}$ & $0,6 \mathrm{Bb}$ \\
\hline & $C V \%=7,27$ & \multicolumn{2}{|c|}{$C V \%=1,75$} & \multicolumn{2}{|c|}{$C V \%=20,10$} & \multicolumn{2}{|c|}{$\mathrm{CV} \%=22,05$} \\
\hline
\end{tabular}

*Médias seguidas de mesma letra, maiúscula na linha e minúscula na coluna, não diferem teste de Tukey $(p \leq 0,05)$.

elongação do tubo polínico, causando a esterilidade de espiguetas, que também depende do tempo de exposição ao estresse térmico, havendo maior índice de esterilidade no período de seis horas do que de duas horas sob estresse a $38^{\circ} \mathrm{C}$ (JAGADISH et al., 2008).

A massa de 1.000 grãos de todos os genótipos, com exceção do cultivar
Epagri 109, foi maior na safra 2017/18 do que na safra 2016/17 (Tabela 3). Temperaturas elevadas após a floração aumentam a atividade respiratória da planta e aceleram o enchimento de grãos, diminuindo a duração deste período (SOSBAI, 2016). Estes dois fatores provavelmente contribuíram para a redução na massa de 1.000 grãos de quatro dos cinco genótipos avaliados na primeira safra.

Observando-se os valores da massa de 1.000 grãos em cada safra, verificouse que na safra 2017/18 não houve diferença entre os genótipos para esta variável. Isto sugere que temperaturas favoráveis ao cultivo de arroz após a floração não afetam a massa de 1.000 
grãos dos genótipos avaliados. Em contrapartida, ao avaliar esta característica na safra 2016/17, cujas temperaturas foram mais elevadas durante o florescimento e o enchimento de grãos, houve diferença significativa entre os genótipos quanto à massa de 1.000 grãos. Nesta safra, os genótipos que se destacaram foram os cultivares Epagri 109 e SCS116 Satoru (Tabela 3), que diferiram significativamente do cultivar SCS122 Miura, que apresentou a menor massa de 1.000 grãos. Os valores de referência para massa de 1.000 grãos dos cultivares avaliados neste estudo são de 28,5, 30,5, 29,9 e 28,6g, para Epagri 109, SCS116 Satoru, SCS121 CL e SCS122 Miura, respectivamente (EPAGRI, 2019). Deste modo, verificou-se que o cultivar Epagri 109 apresentou, em ambas as safras, massa de 1.000 grãos superior ao valor de referência. O contrário foi observado no cultivar SCS116 Satoru, que apresentou valores menores que o de referência, independentemente da safra analisada. Os cultivares SCS121 CL e SCS122 Miura apresentaram o mesmo comportamento, tendo obtido menores valores da massa de 1.000 grãos na safra 2016/17 e maiores na safra 2017/18, comparado aos seus valores de referência (valores apresentados durante o lançamento dos cultivares).

A produtividade dos genótipos avaliados oscilou entre 10.760 e $13.070 \mathrm{~kg}$ ha $^{-1}$ (Tabela 3). A linhagem SC 676 foi a mais produtiva, no entanto não diferiu significativamente dos cultivares SCS122 Miura e SCS116 Satoru. Comportamento semelhante foi observado em trabaIhos conduzidos sob baixas temperaturas por Marschalek et al. (2015; 2019), Souza (2015) e Souza et al. (2017). As menores produtividades foram registradas nos cultivares Epagri 109 e SCS121 CL. Todos os cultivares apresentaram produtividades acima dos valores de referência em seus lançamentos, que foram de $9.500,9.400,10.200$ e $10.400 \mathrm{~kg}$ ha $^{-1}$, para SCS122 Miura, SCS116 Satoru, Epagri 109 e SCS121 CL, respectivamente (EPAGRI, 2019).

A produtividade da segunda safra foi $14 \%$ superior à da primeira, na média dos cinco genótipos (Tabela 2). As temperaturas mais altas registradas durante a antese e o enchimento de grãos em 2016/17 aumentaram a esterilidade de espiguetas (Tabela 2) e reduziram a massa de 1.000 grãos (Tabela 3), como descrito anteriormente, contribuindo para que a produtividade fosse menor em 2016/17 do que em 2017/18.

O percentual de grãos gessados e a área gessada dos grãos apresentaram mesma tendência de resposta. Os maiores valores de gesso foram observados na safra 2016/17, onde ocorreram as maiores temperaturas da antese à coIheita (Tabela 3). Isto comprova que a ocorrência de temperaturas altas durante o período de enchimento de grãos aumenta a incidência de grãos gessados, independentemente do parâmetro utilizado para avaliá-lo.

A percentagem de grãos gessados para os genótipos lançados pela Epagri deve ser menor que 5\% (EPAGRI, 2019). Os valores registrados no trabalho variaram de 1,5 a 17,4\%, dependendo do genótipo e da safra (Tabela 3). Os maiores percentuais foram da linhagem SC 676, em ambas as safras. Os menores valores foram apresentados pelo cultivar SCS121 CL. Os cultivares SCS122 Miura, SCS116 Satoru e Epagri 109 apresentaram valores intermediários e similares em relação ao percentual de grãos gessados, com média de 6,6\% na primeira safra e $3,0 \%$ na segunda. A maior variação observada entre safras foi na linhagem SC 676, onde o percentual de grãos gessados reduziu 3,4 vezes na safra 2017/18, em relação à safra 2016/17. Isto indica que o decréscimo das temperaturas durante o enchimento de grãos foi mais benéfico a este genótipo.

Para área gessada dos grãos, os dados obtidos variaram de 0,6 a 13,8\%, em função da safra e do genótipo avaliado (Tabela 3). A linhagem SC 676 apresentou maior percentual de área gessada nas duas safras. Os menores percentuais foram registrados no cultivar SCS121 CL. Os demais cultivares avaliados apresentaram valor intermediário de área gessada, com médias de 3,9 e 1,7\%, para as safras 2016/17 e 2017/18, respectivamente. A maior diferença entre safras ocorreu na linhagem SC 676, onde houve redução de 5,1 vezes de área gessada dos grãos na segunda safra em relação à primeira.

$O$ rendimento de engenho (percentual de grãos beneficiados: inteiros e quebrados) dos genótipos desenvolvi- dos pela Epagri deve apresentar valores acima de 60\%. Quanto maior esse valor, melhor é a qualidade do produto beneficiado. Os cultivares da Epagri, SCS122 Miura, SCS121 CL, SCS116 Satoru e Epagri 109, apresentam valores referência de $67,5,71,0,70,0$ e 71,0\%, em relação ao rendimento de engenho (EPAGRI, 2019). Nas duas safras o rendimento médio de engenho dos cinco genótipos foi inferior a $70 \%$ (Tabela 2 ).

$\mathrm{O}$ rendimento de engenho foi menor na safra 2016/17 do que na safra seguinte (Tabela 2). Na primeira safra foram registrados os maiores valores de temperatura durante o período de enchimento de grãos. Este resultado vai ao encontro das observações feitas por Shrivastava et al. (2012) e Sreenivasulu et al. (2015), que observaram que o rendimento de engenho em arroz diminui $6 \%$ a cada $1^{\circ} \mathrm{C}$ de aumento na temperatura do ar.

Durante o desenvolvimento dos grãos de arroz, temperaturas elevadas comprometem visual e estruturalmente os grãos. O calor favorece a formação de gesso devido ao acúmulo irregular e pouco compactado dos fotoassimilados no endosperma. Consequentemente, os grãos ficam mais frágeis durante o processamento industrial, aumentando a quebra e diminuindo o rendimento de engenho (ALI et al., 2019; LYMAN et al., 2013; LONDERO et al., 2015; SREENIVASULU et al., 2015; ZHAO \& FITZGERALD, 2013).

De modo geral, os resultados obtidos comprovam as observações feitas por Beckles \& Thitisaksakul (2013) e Londero et al. (2015), de que a aparência do grão de arroz é prejudicada pela elevação da temperatura durante o desenvolvimento do grão. Segundo Lyman et al. (2013), o aumento da temperatura durante o enchimento de grãos fomenta a quebra e o gesso dos grãos e reduz a produtividade. Estes autores constataram que o aumento de 1,2 e $4^{\circ} \mathrm{C}$ na temperatura reduziu a produtividade em até $6,2,13,5$ e 30,0\%, respectivamente.

A temperatura média durante todo o cultivo, em ambas as safras, foi a mesma $\left(28,1^{\circ} \mathrm{C}\right)$. Já a diferença observada nas temperaturas durante o período antese-maturação foi de $2^{\circ} \mathrm{C}$ (Tabela 1 ). Isto ressalta que a diferença obtida no 
percentual de esterilidade, na produtividade e na qualidade de grãos entre as safras deveu-se, principalmente, à ocorrência de temperaturas superiores na primeira safra, tanto na floração quanto durante o enchimento de grãos.

Os dados relacionados a produtividade e qualidade de grãos demonstram resultado inversamente proporcional à esterilidade. Assim, pode-se inferir que o aumento de esterilidade reduz a produtividade e a qualidade de grãos, o que também foi observado por Beckles \& Thitisaksakul (2013), Eberhardt (2010), Shrivastava et al. (2012) e Sreenivasulu et al. (2015).

\section{Conclusões}

A produtividade e a qualidade de grãos dos genótipos avaliados diminuíram na safra que apresentou maior temperatura média e máxima na antese e na fase de enchimento de grãos.

A linhagem SC 676 destacou-se como o genótipo mais produtivo e o que apresentou maior aumento no gesso na safra com temperatura média mais alta.

\section{Agradecimentos}

À Epagri/EEl e à equipe do Projeto Arroz, pela parceria, pelo apoio ao planejamento e toda a infraestrutura para o desenvolvimento dos experimentos.

\section{Referências}

ALI, F.; WATERS, D.L.E.; OVENDEN, B.; BUNDOCK, P.; RAYMOND, C. A.; ROSE, T.J. Heat stress during grain fill reduces head rice yield through genotype dependant increased husk biomass and grain breakage. Journal of Cereal Science, London, v.90, p.1-7, 2019. DOI: 10.1016/j.jcs.2019.102820

BECKLES, D.M.; THITISAKSAKUL, M. How environmental stress affects starch composition and functionality in cereal endosperm. Starch Journal, Weinheim, v.65, p.1-14, 2013. DOI: 10.1002/star.201300212

CHEN, J.; YAN, H.; MU, Q.; TIAN, X. Impacts of prolonged high temperature on heavypanicle rice varieties in the field. Chilean Journal of Agricultural Research, Chillán, v.77, n.2, p.102-109, 2017. DOI: 10.4067/ S0718-58392017000200102
COUNCE, P.A.; KEISLING, T.C.; MITCHELL, A.J.A uniform, objective, and adaptive system for expressing rice development. Crop Science, Madison, v.40, n.4, p.436-443, 2000. DOI: $n / d$

EBERHARDT, D.S. Altas temperaturas afetam produtividade e qualidade do arroz irrigado no estado. Revista Agropecuária Catarinense, Florianópolis, v.23, n.2, p.12, 2010.

EPAGRI - Empresa de Pesquisa Agropecuária e Extensão Rural de Santa Catarina. Publicações. Florianópolis, SC, 2020. Disponível em <https://www.epagri.sc.gov.br/ index. php/solucoes/publicacoes/folder-tecnico/> Acesso em: 02 jan. 2019.

INMET - Instituto Nacional de Meteorologia. Estações Automáticas. Brasília, DF, 2019. Disponível em: http://www.inmet.gov.br/ portal/index.php?r=estacoes/estacoes Automaticas. Acesso em: 02 jan. 2019.

JAGADISH, S.V.K.; CRAUFURD, P.Q.; WHEEL$E R$, T.R. Phenotyping parents of mapping populations of rice for heat tolerance during anthesis. Crop Science, Madison, v.48, p.1140-1146, 2008. DOI: 10.2135/cropsci2007.10.0559

LONDERO, G.P.; MARCHESAN, E.; PARISOTTO, E.; COELHO, L.L.; ARAMBURU, B.B.; FLORES, C.S.; SILVA, A.L. Qualidade industrial de grãos de arroz decorrente da supressão da irrigação e umidade de colheita. Irriga, Botucatu, v.20, n.3, p.587-601, 2015.

LYMAN, N.B.; JAGADISH, K.S. V.; NALLEY, L.L.; DIXON, B.L.; SIEBENMORGEN, T. Neglecting rice milling yield and quality underestimates economic losses from high-temperatures stress. Plos One, San Francisco, v.8, n.8, p.1-9, 2013. DOI: 10.1371/journal. pone.0072157

MARSCHALEK, R.; ROZZETTO, D.S.; ANDRA$D E, A . ;$ WICKERT, E. Avaliação de genótipos de arroz irrigado em região de elevada altitude, sujeitos a baixas temperaturas 2013/14 - 2014/15. In: CONGRESSO BRASILEIRO DE ARROZ IRRIGADO, 9., 2015. Pelotas. Anais[...] Pelotas, 2015. p.116-119.

MARSCHALEK, R; SOUZA, N.M.; WICKERT, E.; ANDRADE, A.; TERRES, L.R.; MASSIGNAM, A.M.; RICCE, W.S.; SANGOI, L. Produtividade de cultivares e linhagens de arroz irrigado em região de altitude, sujeita a baixas temperaturas, safras 2017/18 e 2018/19. In: CONGRESSO BRASILEIRO DE ARROZ IRRIGADO, 11., 2019. Balneário Camboriú. Anais[...]
Balneário Camboriú, 2019. p.129-132.

NGUYEN, D.N.; LEE, K.J.; KIM, D.I.; ANH, N.T.; LEE, B.W. Modeling and validation of high-temperature induced spikelet sterility in rice. Field Crops Research, Stockholm, v.156, p.293-302, 2014. DOI: 10.1016/j. fcr.2013.11.009

SHRIVASTAVA, P.; SAXENA, R.R.; XALXO, M.S.; VERULKAR, S.B. Effect of high temperature at different growth stages on rice yield and grain quality traits. Journal of Rice Research, Rajendra Nagar, v.5, n.1 e 2, p.29-42, 2012.

SILVA, F.A.S.; AZEVEDO, C.A.V. The Assistant Software Version 7.7 and its use in the analysis of experimental data. African Journal of Agricultural Research, Lagos, v.11, n.39, p.3733-3740, 2016.

SOCIEDADE SUL-BRASILEIRA DE ARROZ IRRIGADO (SOSBAI). Arroz irrigado: Recomendações técnicas da pesquisa para o sul do Brasil. Pelotas, RS: SOSBAI. 2016. 200p.

SOUZA, N.M. Tolerância a baixas temperaturas na fase de microsporogênese em genótipos de arroz irrigado. 2015. 93 p. Dissertação (Mestrado em Produção Vegetal) - Universidade do Estado de Santa Catarina, Centro de Ciências Agroveterinárias, SC, 2015.

SOUZA, N.M.; MARSCHALEK, R.; SANGOI, L.; WEBER, F.S. Spikelet sterility in rice genotypes affected by temperature at microsporogenesis. Revista Brasileira de Engenharia Agrícola e Ambiental, Campina Grande, v.21, n.12, p.817-821, 2017. DOI: 10.1590/18071929/agriambi.v21n12p817-821

SREENIVASULU, N.; BUTARDO JUNIOR, V.M.; MISRA, G.; CUEVAS, R.P.; ANACLETO, R.; KISHOR, P.B.K. Designing climate-resilient rice with ideal grain quality suited for hightemperature stress. Journal of Experimental Botany, Oxford, v.66, n.7, p.1737-1748, 2015. DOI: 10.1093/jxb/eru544

VAN OORT, P.A.J.; SAITO, K.; ZWART, S.J.; SHRESTHA, S.A simple model for simulating heat induced sterility in rice as a function of flowering time and transpirational cooling. Field Crops Research, Stockholm, v.156, p.303-312, 2014. DOI: 10.1016/j. fcr.2013.11.007

ZHAO, X.; FITZGERALD, M. Climate change: implications for the yield of edible rice. Plos One, San Francisco, v.8, n.6, p.1-9, 2013. DOI: $10.1371 /$ journal.pone.0066218. 